\title{
F Fermilab
}

\section{RESIDUAL RADIATION STUDIES AT AP0}

\author{
A. Elwyn, N. Grossman, K.Vaziri, and V. Cupps \\ June 6, 2002
}

\section{Introduction}

The radiation environment at the NuMI experiment has received a lot of attention in the last few years in preparation for project construction. One important issue is the induced radioactivation of the components in the beam line and the shielding materials. This arises from irradiation by hadrons that are generated in the target. Since the level of the residual activity has to be considered when determining access procedures for maintenance during NuMI operation, an understanding of the properties of the remanent radiation is important.

To this end, experimental studies were performed in the target vault at AP0 which is similar in design to the NuMI target area. Here $120 \mathrm{GeV}$ protons bombard a target, generating the hadrons that produce the induced radioactivity. Two sets of samples each consisting of three small cylindrical or rectangular solids of iron and steel, one sample of aluminum, and one of concrete were irradiated. One set was hung just below the bottom of a module near the lithium lens (in-vault), and the other was placed on top of the modules downstream of this location (above-vault), just beneath the movable concrete roof of the vault at $\mathrm{AP0}$. Further, four thin activation foils of $\mathrm{Au}, \mathrm{Au}+\mathrm{Cd}, \mathrm{In}$, and $\mathrm{Al}$ (along with small disks of the same iron, aluminum, and concrete samples discussed above) were mounted on four $10.2 \mathrm{~cm}$ diameter $\mathrm{Al}$ disks, one placed on the in-vault module and three ${ }^{1}$ at abovevault downstream locations as well. The radioactivity of all these materials on the $10.2 \mathrm{~cm}$ Al disks was determined at the Radioisotope Analysis Facility in an attempt to characterize the radionuclides produced during irradiation. The activities of the thin foils were employed in an effort to unfold a spectrum of the neutrons produced during the hadronic cascades in the target.

The MARS Monte Carlo code (MO95, MO00) was used to predict and analyze the residual radiation produced during the beam irradiation. New subroutines have been developed for the MARS14 version providing reliable estimation of residual dose rates in arbitrary composite materials for arbitrary irradiation and cooling times (RA01). The results of the simulations have been compared with the measurements in Ref. (RA01) and this comparison will be summarized here.

\footnotetext{
${ }^{1}$ Two of the three $\mathrm{Al}$ disks placed on the top of the modules were enclosed in polyethylene $\left(\mathrm{CH}_{2}\right)$ boxes.
} 


\section{Procedure}

\section{(a). In-Vault (i.e., near beam) Irradiation}

For the in-vault studies, the five samples mentioned above were attached to the lower part of a test fixture that was installed on the bottom of the module just downstream of the lithium lens module in the AP0 vault, about $61 \mathrm{~cm}$ downstream of the pbar target. The samples were 1018 Steel (\#ST4-2.5 cm diam. by $7.65 \mathrm{~cm}$ high cylinder), Iron (\#FE4-2.7 $\mathrm{cm}$ diam. by $3.85 \mathrm{~cm}$ high cylinder), A500 Steel (\#A500-5 cm by $2.5 \mathrm{~cm}$ by $1.15 \mathrm{~cm}$ rectangular solid), 6061 Aluminum (\#AL4-2.5 cm diam. by $7.65 \mathrm{~cm}$ high cylinder), and concrete (\#C2- $2.5 \mathrm{~cm}$ diam. by $1.6 \mathrm{~cm}$ high cylinder). Further, the thin (approximately $0.013 \mathrm{~cm}$ thick) $2.54 \mathrm{~cm}$ diameter activation foils of $\mathrm{Au}$, $\mathrm{Au}$ covered with $\mathrm{Cd}$, In, and $\mathrm{Al}$ were mounted on a $10.2 \mathrm{~cm}$ diameter disk and attached to the upper part of the test fixture; these foils, after activation, were used to estimate the spectrum of neutrons, including the thermal neutron component, within the vault. Small $(2.54 \mathrm{~cm}$ diam., $0.32 \mathrm{~cm}$ thick) disks of the various samples described above were also mounted on this disk, and later analyzed for their radioisotope content; the results are shown in Appendix 1.

The in-vault samples were irradiated for a total of 37.67 hours with a total intensity of 1.34 $\mathrm{x} 10^{17}$ protons incident on the AP0 target. Table 1 presents a summary of the irradiation conditions. $^{2}$

Table 1: Summary of Irradiation Time and Proton Intensity on the Pbar Target.

\begin{tabular}{|l|l|l|l|l|l|}
\hline Start Date & Start Time & End Date & End Time & $\begin{array}{l}\text { Irradiation Time } \\
\text { (hours) }\end{array}$ & $\begin{array}{l}\text { Integrated } \\
\text { Intensity (protons }\end{array}$ \\
\hline $6 / 22 / 00$ & 1220 & $6 / 23 / 00$ & 0440 & 16.17 & $4.96 \times 10^{16}$ \\
\hline $6 / 27 / 00$ & 0400 & $6 / 27 / 00$ & 1430 & 10.5 & $2.76 \times 10^{16}$ \\
\hline $6 / 27 / 00$ & 2130 & $6 / 28 / 00$ & 0830 & 11 & $5.67 \times 10^{16}$ \\
\hline & & Totals & 37.67 & $1.34 \times 10^{17}$ \\
\hline
\end{tabular}

The samples were removed from the fixture on 6/28/00 at about 11:00 AM, 26.5 hours after the end of the irradiation. They were transported to the Target Service Building (TSB) for counting, and the first reliable counting rate measurements were started after about 3 hours, or 29.5 hours after the irradiation was over. Counting rates were determined by use of standard Fermilab survey instruments: a Bicron Analyst (3.81 x $2.54 \mathrm{~cm} \mathrm{NaI}$ scintillator + phototube) count rate meter, a Nucleus (AC powered scaler and thin window GM tube) count rate meter, and a Fredron (Ludlum 14C with 2 energy-compensated GM tubes) survey meter that measures dose rate directly rather than counting rate.

Counting rate measurements were performed at distances of both one and two feet (30.5 and $61 \mathrm{~cm}$ ) from each sample (depending upon which instrument was used) at times after

${ }^{2}$ A $0.008 \mathrm{~cm}$ thick aluminum foil was placed at the center of the test fixture. The ${ }^{22} \mathrm{Na}$ activity of this foil was determined at the Radioisotope Analysis Facility to be $2.56 \times 10^{6} \mathrm{pC}_{\mathrm{i}} / \mathrm{gram}$ (LE00). On the assumption that the cross section for the production of ${ }^{22} \mathrm{Na}$ from $\mathrm{Al}$ is the same $(\sim 10 \mathrm{mb})$ for all particles (e.g, protons, neutrons, pions, etc.) incident on the foil, then the particle flux at the center of the test fixture was found to be $3.7 \times 10^{11} \mathrm{~cm}^{-2} \mathrm{sec}^{-1}$. This corresponds to an irradiating fluence of particles equal to $0.38 \mathrm{~cm}^{-2}$ per proton incident on the target 
irradiation that varied from 29.5 to 797 hours. Dose rate measurements with the Fredron were only performed at a distance of one foot. Net counting rates and dose rates were determined from measured background rates. Deadtime effects were negligibly small at the counting rates measured at these distances. Cooling curve results for all samples are shown in Figs. 1-6. It should be noted that the results obtained with all instruments for each sample are very similar in shape.

\section{(b). Above-Vault Irradiation}

One set of samples, similar to those attached to the test module in the vault (except that the concrete sample was only $0.3 \mathrm{~cm}$ high), was placed at a location on top of the $183 \mathrm{~cm}$ high steel shielding modules about $100 \mathrm{~cm}$ downstream from the in-vault location. It was placed on an open Al tray along with a $10.2 \mathrm{~cm}$ diameter Al disk holding thin foils and small sample disks, as in the in-vault irradiation. Two similar Al disks were placed in 2 inch $(5.08 \mathrm{~cm})$ and 6 inch $(16.8 \mathrm{~cm})$ thick rectangular $\mathrm{CH}_{2}$ boxes at above vault locations near the open tray. All samples were irradiated for, on the average, 16 hours followed by 26 hours off for about four months with a total of approximately $3.6 \times 10^{18}$ protons incident on the in-vault target. After the last irradiation, the rectangular and cylindrical samples from the open Al tray were removed to a low-background area and contact counting rate and dose rate measurements were performed with the Bicron and Fredron instruments. Counting was started between two and five hours after the end of the irradiation. The cooling curves for the samples, based on the measurements, are shown in Figs. 7-10. Results of the analysis of the radioisotopes in the irradiated $2.54 \mathrm{~cm}$ diameter disks of the samples, is shown in Appendix 1.

\section{Cooling Curve Results and Discussion}

\section{(a). In-Vault Irradiation}

Figs. 1 - 3 show the in-vault results for the iron and steel samples at a distance of both one and two feet from the samples. Their cooling characteristics are very similar although the materials contain different trace elements. Sample FE4 is "pure" iron. ST4 is M1018 steel which contains $0.15-0.2 \%$ carbon and 0.6-0.9 \% manganese with $0.045 \%$ each of phosphorus and sulfur. The NuMI target station modules were going to be fabricated from this material. The sample A500 has $0.26 \%$ carbon and $0.045 \%$ each of phosphorus and sulfur. There is no manganese in it, but it does contain $0.2 \%$ copper. The solid curves on Figs. $1-3$ represent exponential fits to the measured net count rates and dose rates on the assumption that the cooling can be represented primarily (see Appendix 1) by the decay of both the 2.44 day half life $\left(\lambda=0.0118 \mathrm{~h}^{-1}\right){ }^{44} \mathrm{Sc}$ and the 5.6 day half life $\left(\lambda=0.00516 \mathrm{~h}^{-1}\right)$ ${ }^{52} \mathrm{Mn}$, along with the 27.7 day half life $\left(\lambda=0.00104 \mathrm{~h}^{-1}\right){ }^{51} \mathrm{Cr}$. The inclusion of other isotopes shown in the table in Appendix 1 does not improve the agreement. It is obvious that any short-lived radioisotopes (with half lives less than about 10 hours) could not have been observed since the counting was not started until 29 hours after the end of the irradiation. Furthermore, the inclusion of 312 day half life ${ }^{54} \mathrm{Mn}\left(\lambda=9.25 \times 10^{-5} \mathrm{~h}^{-1}\right)$, while perhaps reasonable, is not well determined as the irradiation lasted for only about 38 hours, and the cooling was followed for only about a month. Nevertheless, the fits are excellent, 
and the general similarity for the different samples suggests that the trace elements of which they are composed do not play a large role in their decay characteristics. It is not completely clear why the ratios of the coefficients associated with the fits are different depending on the instrument used for the measurement. However, the instruments are based on different detection techniques (see Section 2), which respond to the range of gamma (and beta) energies differently from each other.

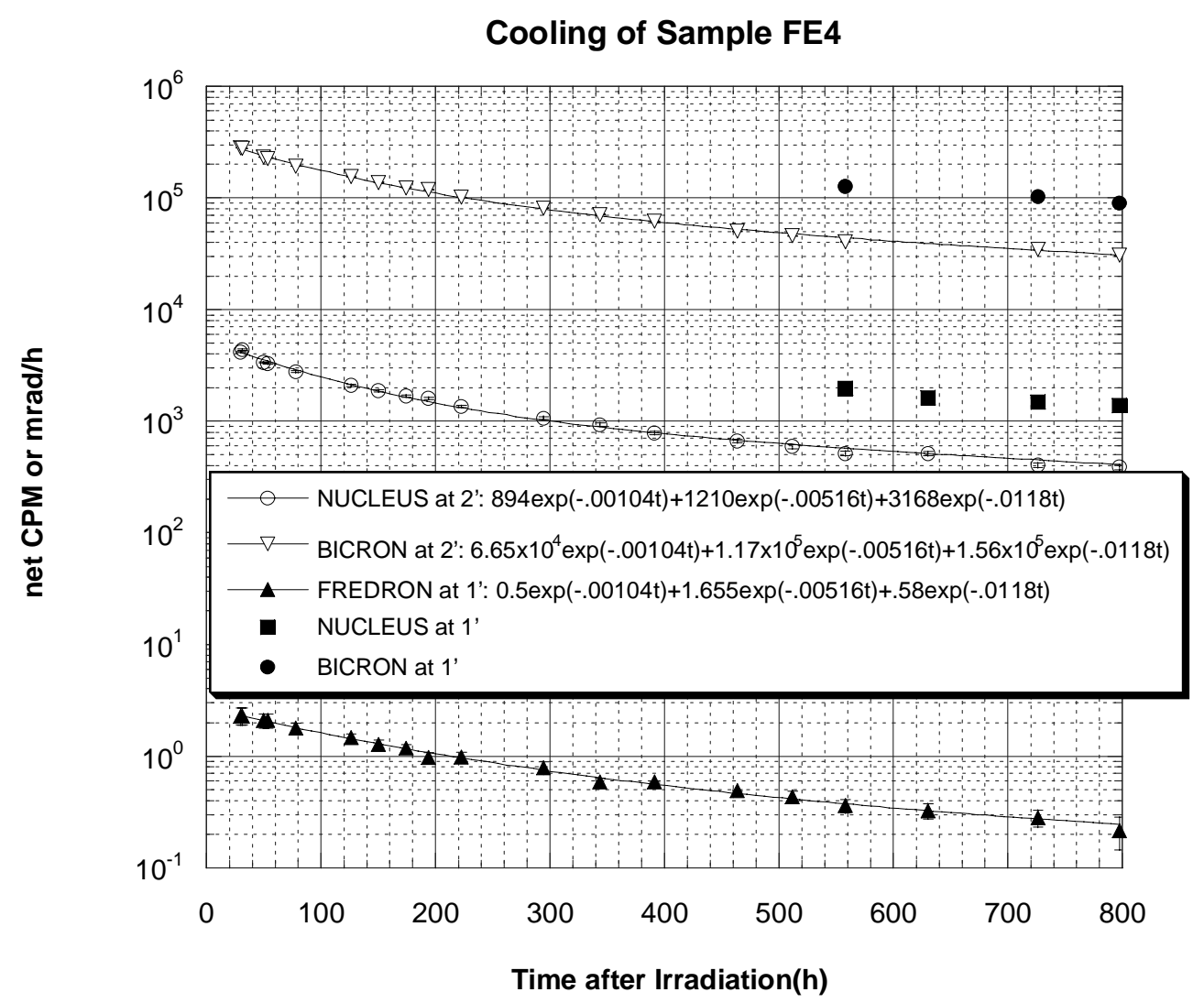

Fig.1. Cooling of sample FE4 ("pure" iron) as a function of time after irradiation 


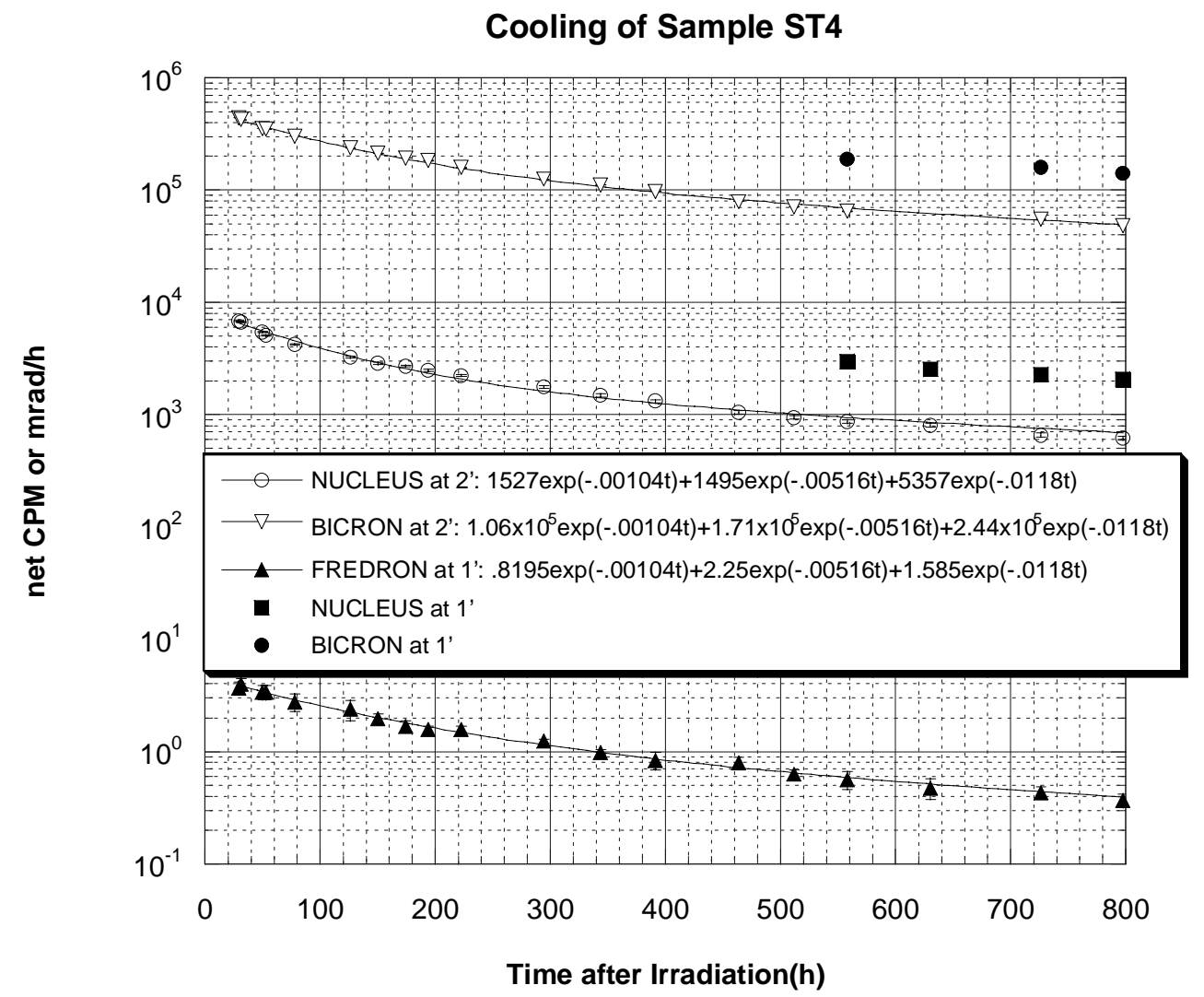

Fig.2. Cooling of sample ST4 (1018 steel) as a function of time after irradiation 




Fig. 3. Cooling of sample A500 (A500 steel) as a function of time after irradiation.

Fig. 4 shows the results for the aluminum sample, AL4. The solid curves represent exponential fits to the data from each instrument. From the amplitudes for the two terms in the fit, the decay is clearly dominated by the 15 -hour half life $\left(\lambda=0.046 \mathrm{~h}^{-1}\right){ }^{24} \mathrm{Na}$ isotope. The second isotope, the 53.3-day $\left(\lambda=5.42 \times 10^{-4} \mathrm{~h}^{-1}\right){ }^{7} \mathrm{Be}$, represents less than $0.5 \%$ of the ${ }^{24} \mathrm{Na}$ activity. This result is in agreement with the radioisotope analysis of the $2.54 \mathrm{~cm}$ diameter Al disk (see Appendix 1). The sample of Al contains 1\% magnesium, $0.8 \%$ each of copper and silicon, and $0.5 \%$ manganese. The dose rates measured with the Fredron are almost down to background rates at times after irradiation of about 300 hours. 


\section{Cooling of Sample AL4}

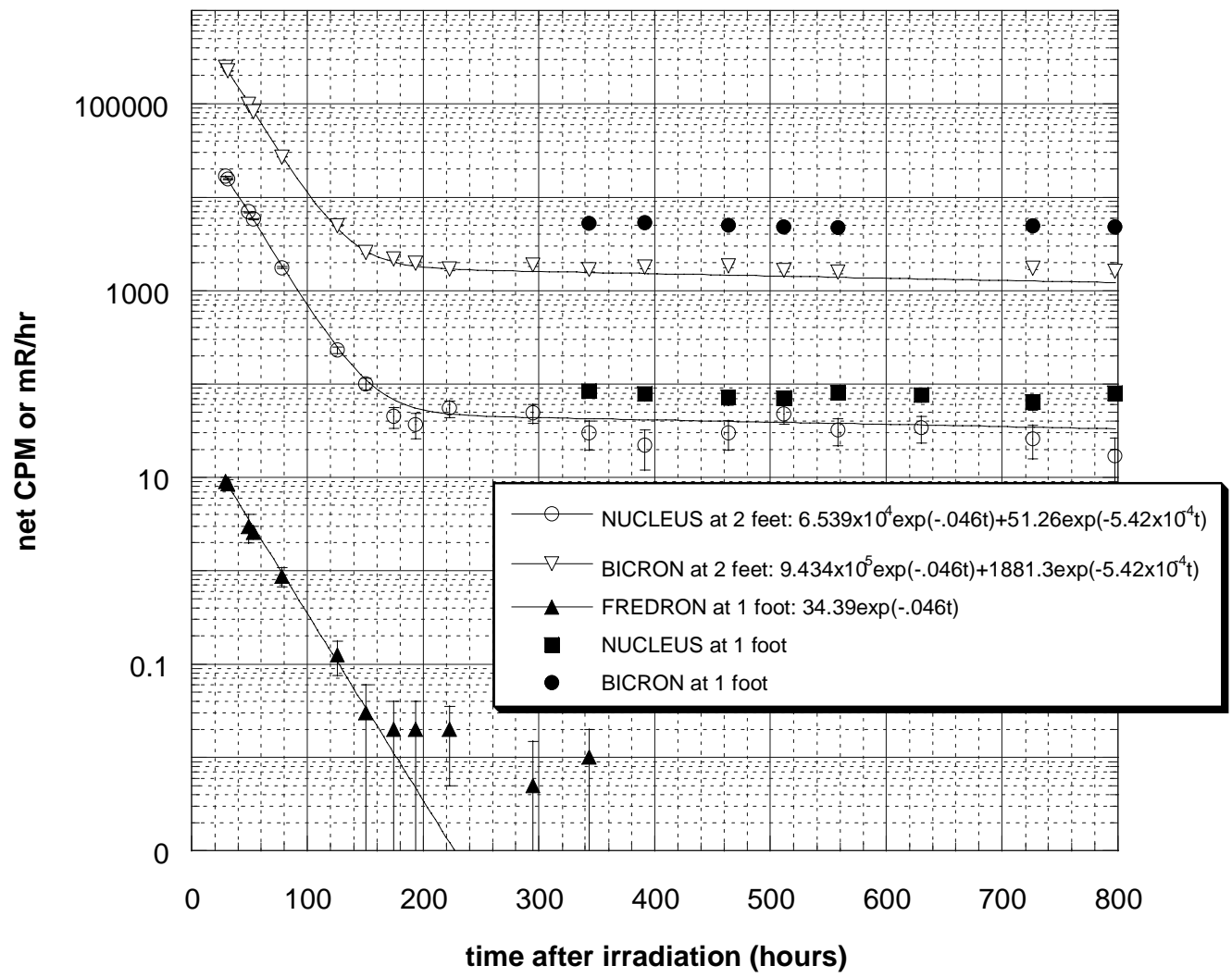

Fig. 4. Cooling of sample AL4 (aluminum) as a function of time after irradiation.

Figs. 5 and 6 show the 1 foot and 2 foot data, respectively, for the concrete sample C2. Fredron rates at the 2 foot distance were very close to background rates and are not shown. The solid curves on both figures represent exponential fits again dominated by the decay of 15 -hour ${ }^{24} \mathrm{Na}$. The 53.3 -day ${ }^{7} \mathrm{Be}$ activity is less than $0.5 \%$ of the ${ }^{24} \mathrm{Na}$ activity, as for the sample AL4. The dotted curve for the Fredron data is based on a fit to data upto about 200 hours after irradiation (after which time the Fredron C2 measurements approach background values) for the 15 -hour ${ }^{24} \mathrm{Na}$ decay only; the extension of the curve to longer times arises from the addition of the ${ }^{7} \mathrm{Be}$ decay with an intensity derived from the ratios of ${ }^{7} \mathrm{Be}$ to ${ }^{24} \mathrm{Na}$ amplitudes from fits to the Bicron and Nucleus data. Radioisotope analysis of the concrete sample suggests that ${ }^{7} \mathrm{Be}$ represents about $20 \%$ and ${ }^{42} \mathrm{~K}$ and ${ }^{43} \mathrm{~K}$ each $3-4 \%$ of the ${ }^{24} \mathrm{Na}$ activity (see Appendix 1). 


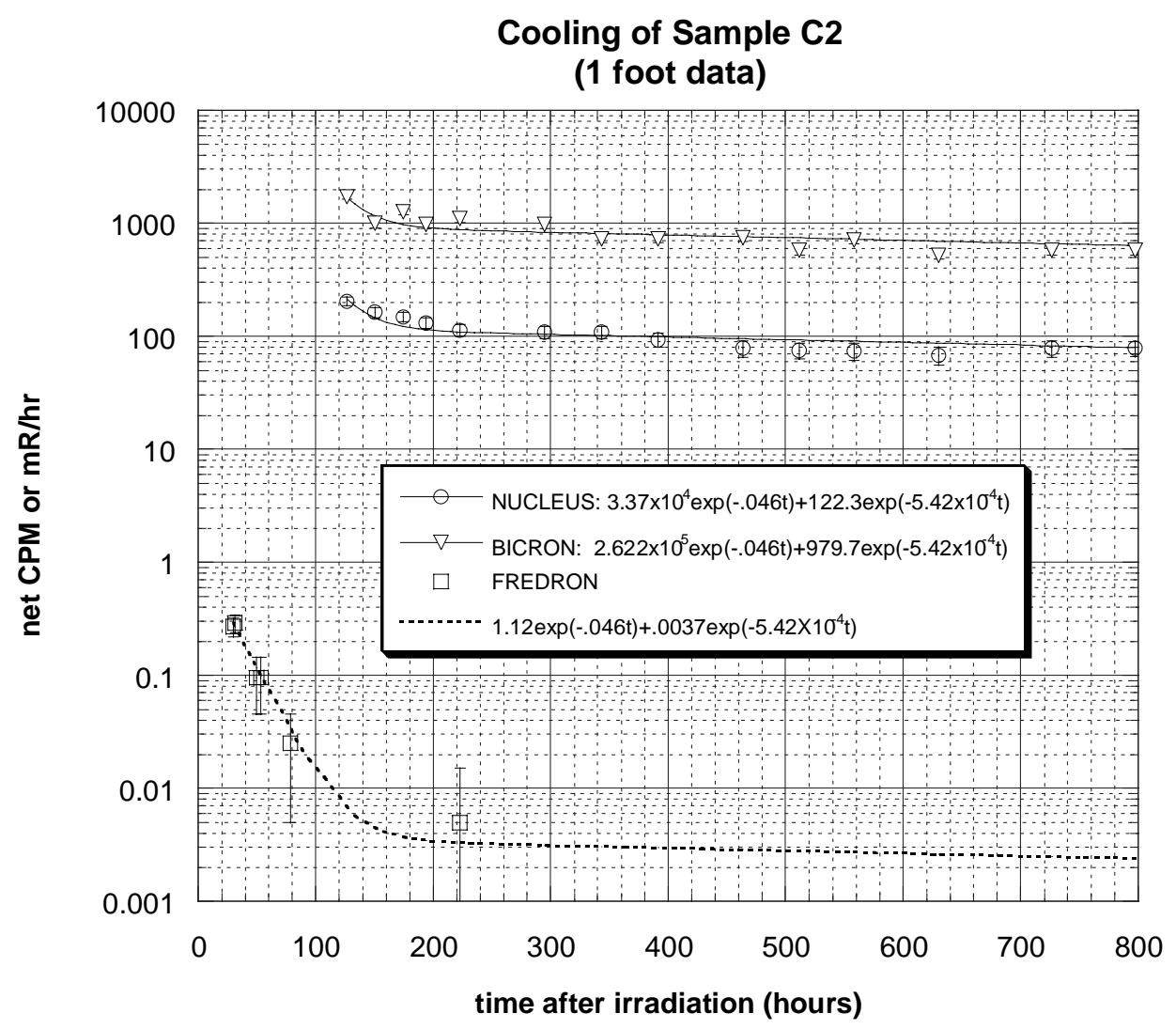

Fig. 5. Cooling of sample $\mathrm{C} 2$ (concrete) as a function of time after irradiation. The data represents measurements at a distance of 1 foot from the sample. 


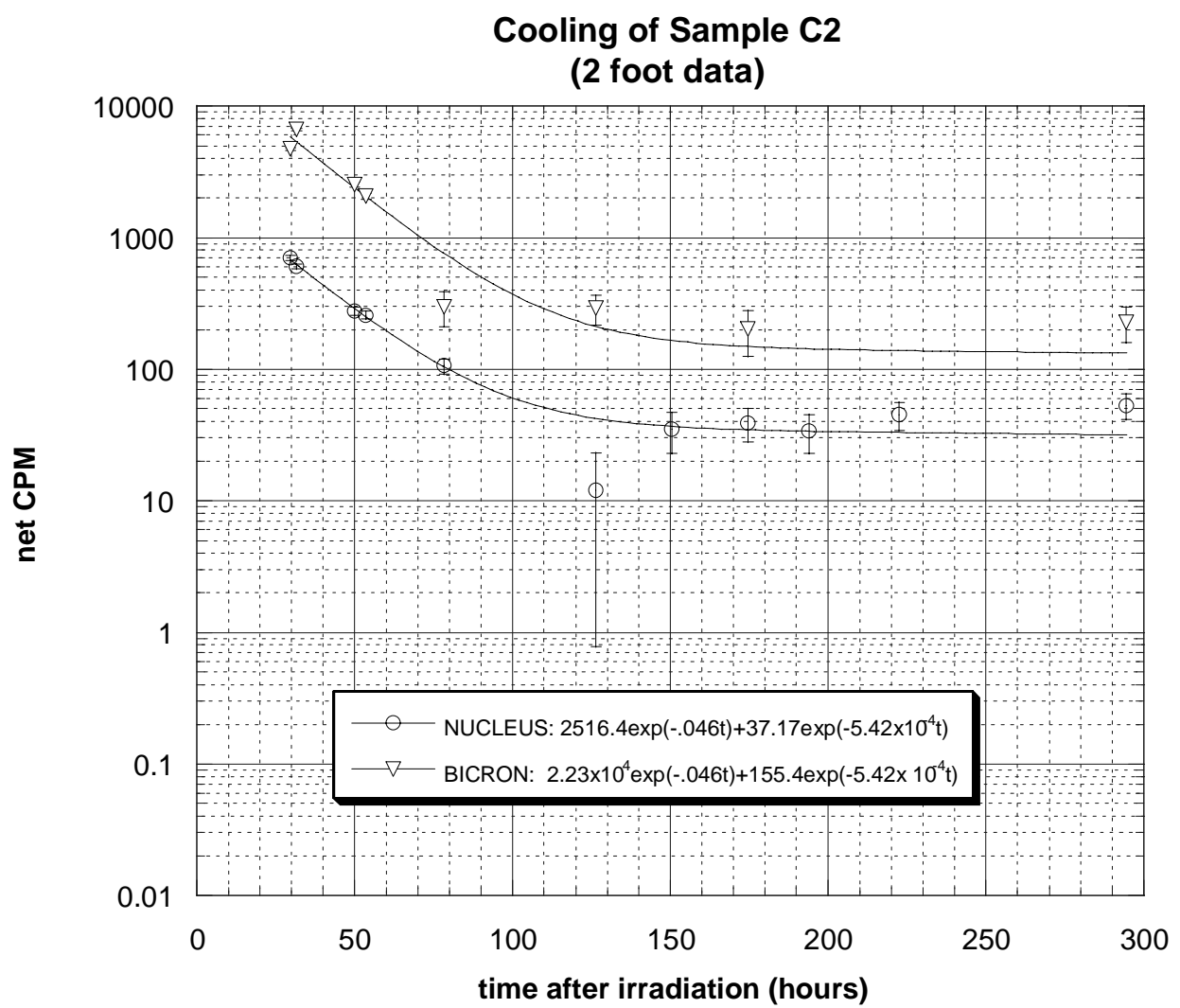

Fig. 6. Cooling of sample C2 (concrete) as a function of time after irradiation. The data represent measurements at a distance of 2 feet from the sample.

\section{(b). Above-Vault Irradiation}

Figs. 7-10 show the above-vault results for the cooling of the various samples based on both the Bicron and Fredron instrument measurements. The three different iron-like samples (Figs. 7 and 8 ) yield very similar cooling characteristics. The fit to the measurements is dominated by the production of the 2.6 hour $\left(\lambda=0.269 \mathrm{~h}^{-1}\right)^{56} \mathrm{Mn}$ isotope and is improved by the addition of 44.5 day $\left(\lambda=6.4 \times 10^{-4} \mathrm{~h}^{-1}\right){ }^{59} \mathrm{Fe}$. For the two steel samples this is in agreement with the results shown in Appendix 1. For Fe, on the other hand, no ${ }^{56} \mathrm{Mn}$ was observed in the disk sample although it contributes to the cooling curve fits. This can be understood because the Fe disk sample was not analyzed until more than 48 hours after removal from the beam so that any short-lived activity, such as the 2.6 hour ${ }^{56} \mathrm{Mn}$ would not have been observed. 


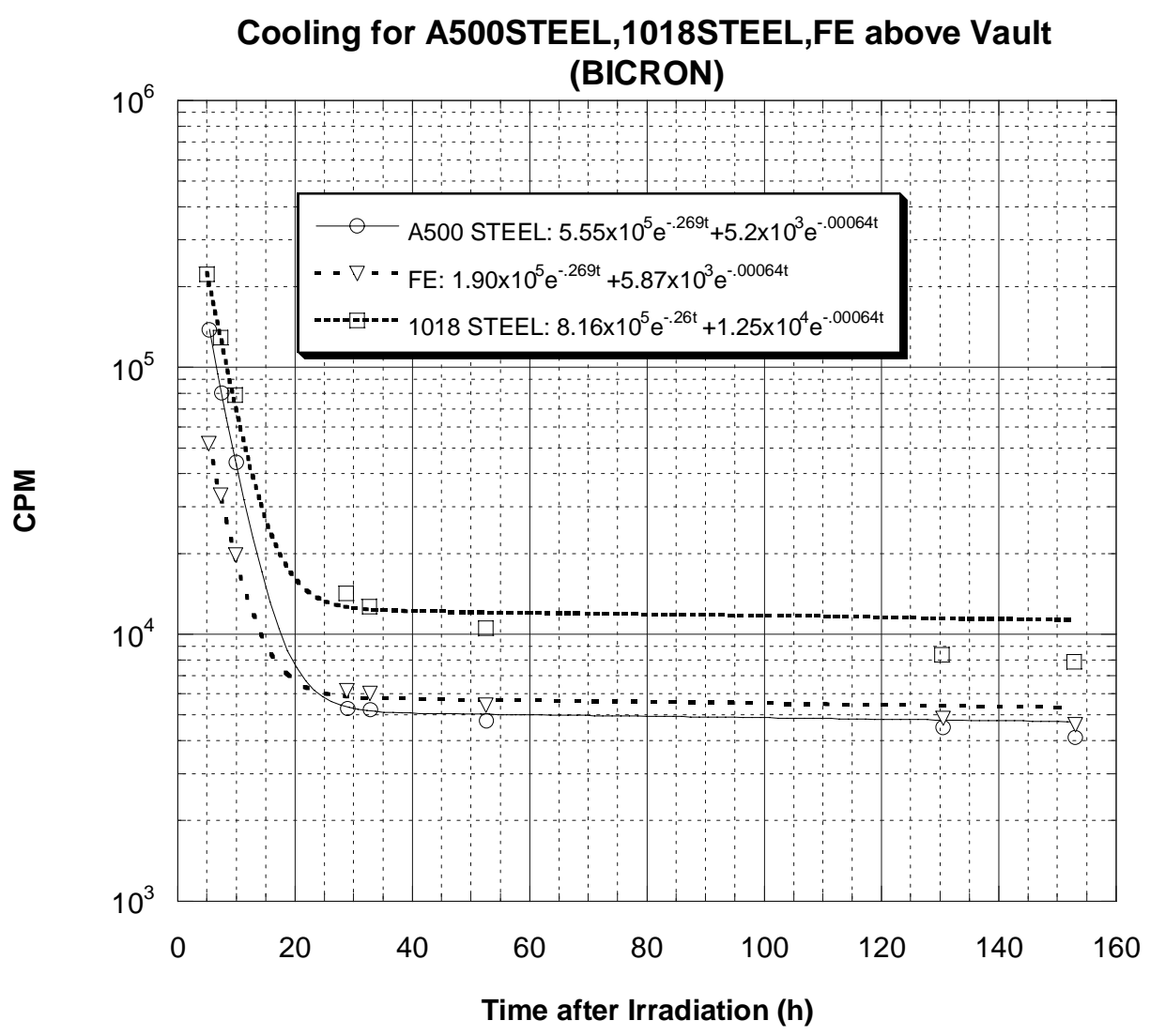

Fig. 7. Cooling of iron-like samples as a function of time after above vault-shielding irradiation. The data represent contact Bicron counting rate readings. 


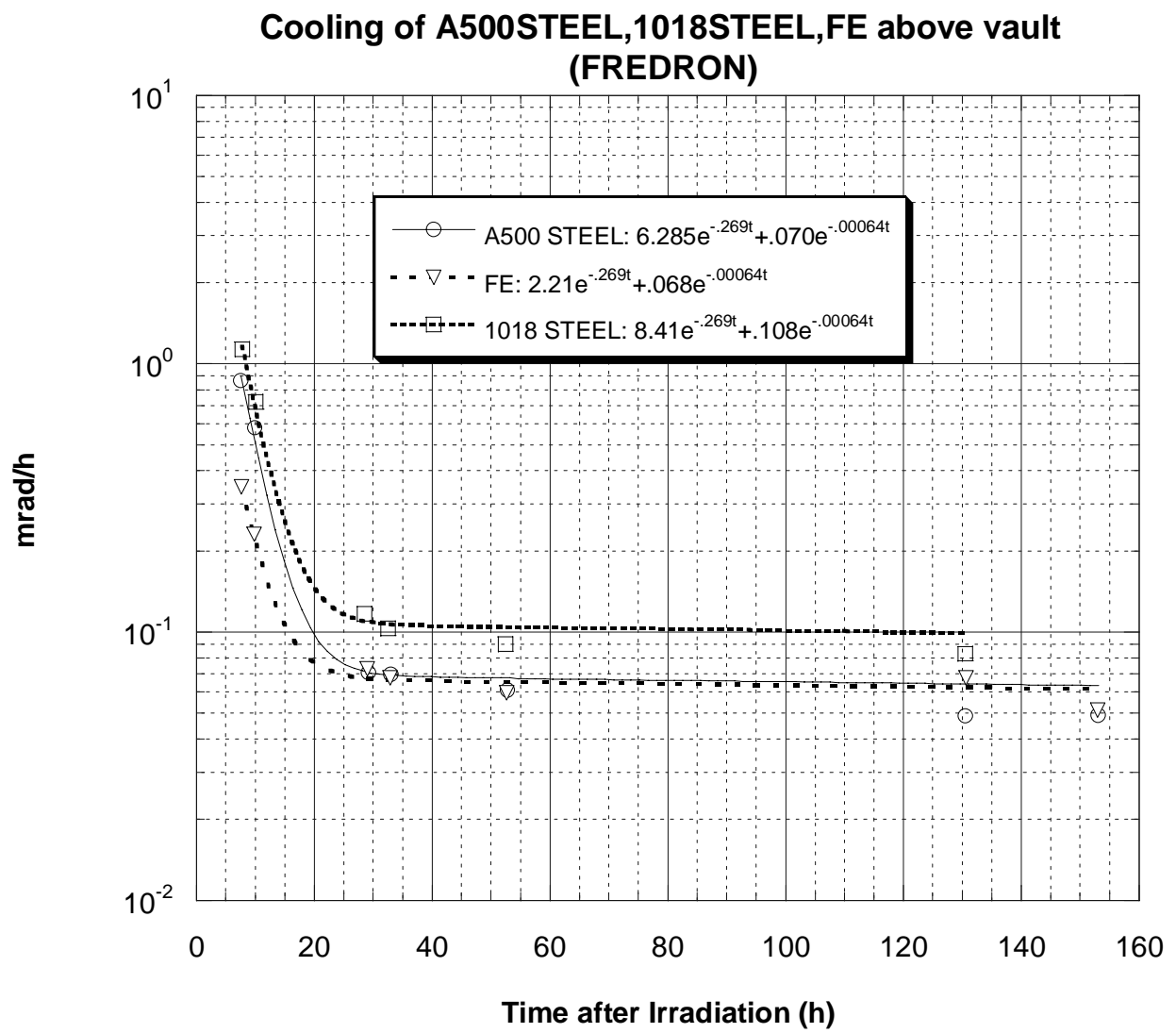

Fig. 8. Cooling of iron-like samples as a function of time after above vault-shielding irradiation. The data represent Fredron contact dose rate readings.

The interpretation of the results for the aluminum and concrete samples (Figs. 9 and 10) is less certain. The best fit to the data for aluminum suggests that the cooling curve is represented by an isotope with a half-life of about 2.6 hours $\left(\lambda=0.26 \mathrm{~h}^{-1}\right)$ along with the expected 15 -hour ${ }^{24} \mathrm{Na}$ (and perhaps a hint of the 53.3 -day ${ }^{7} \mathrm{Be}$ ), with the amplitude for the 2.6 hour half life somewhat larger than for ${ }^{24} \mathrm{Na}$. However, the closest isotope with a 2.6hour half life is ${ }^{31} \mathrm{Si}$ which is not expected to be produced by hadrons on an $\mathrm{Al}$ target unless there is a sizeable impurity present. On the other hand the isotope ${ }^{18} \mathrm{~F}$, with a half-life of $1.83 \operatorname{hours}^{3}\left(\lambda=0.38 \mathrm{~h}^{-1}\right)$, can be produced in an Al sample. The Bicron results for the concrete sample are consistent with the above remarks although the data is not complete enough to really determine the ${ }^{7} \mathrm{Be}$ contribution. It might be possible, however, to produce ${ }^{31} \mathrm{Si}$ from the heavier nuclides that make up the composition of concrete. The Fredron

\footnotetext{
${ }^{3}$ The data is not complete enough to distinguish a 1.8-hour from a 2.6-hour half life.
} 
results are not complete enough to determine any contribution beyond that of the approximately 2-hour decay. No ${ }^{18} \mathrm{~F}$ or ${ }^{31} \mathrm{Si}$ activity was observed in the radioisotope analysis of the small disks shown in Appendix 1, where the only activity above-vault was that due to ${ }^{24} \mathrm{Na}$ (for the $\mathrm{Al}$ sample) and ${ }^{24} \mathrm{Na}$ and ${ }^{42} \mathrm{~K}$ (for concrete). However, the analysis of the $\mathrm{Al}$ and concrete disks was not started for about 29 hours after the irradiation ended, which represents about 15 half lives in the decay of a 2-hour activity, and so, as with the Fe disk sample, it is not likely that such activity would have been observed.

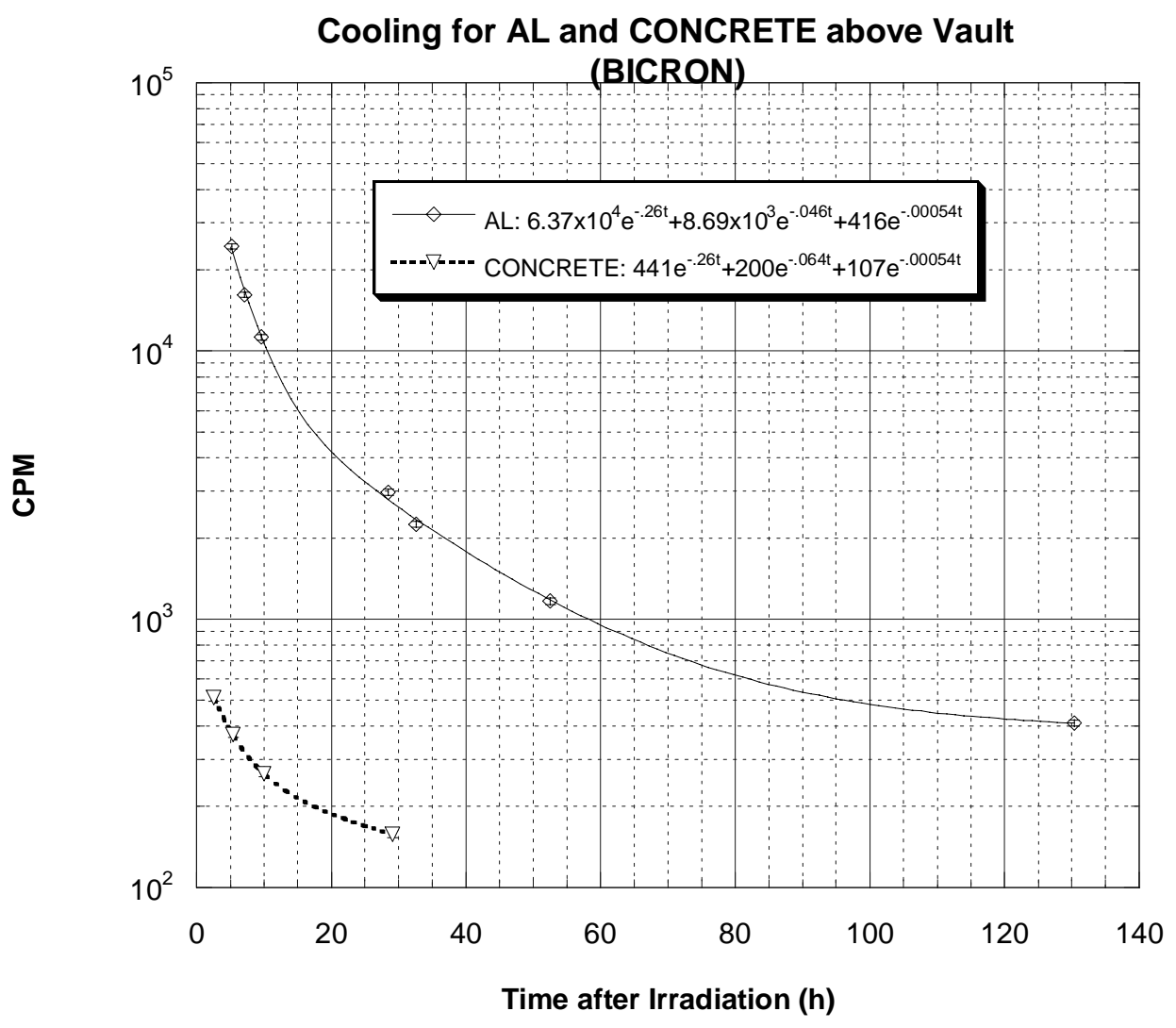

Fig. 9. Cooling of Al-like samples as a function of time after above vault-shielding irradiation. The data represent Bicron contact counting rate readings. 


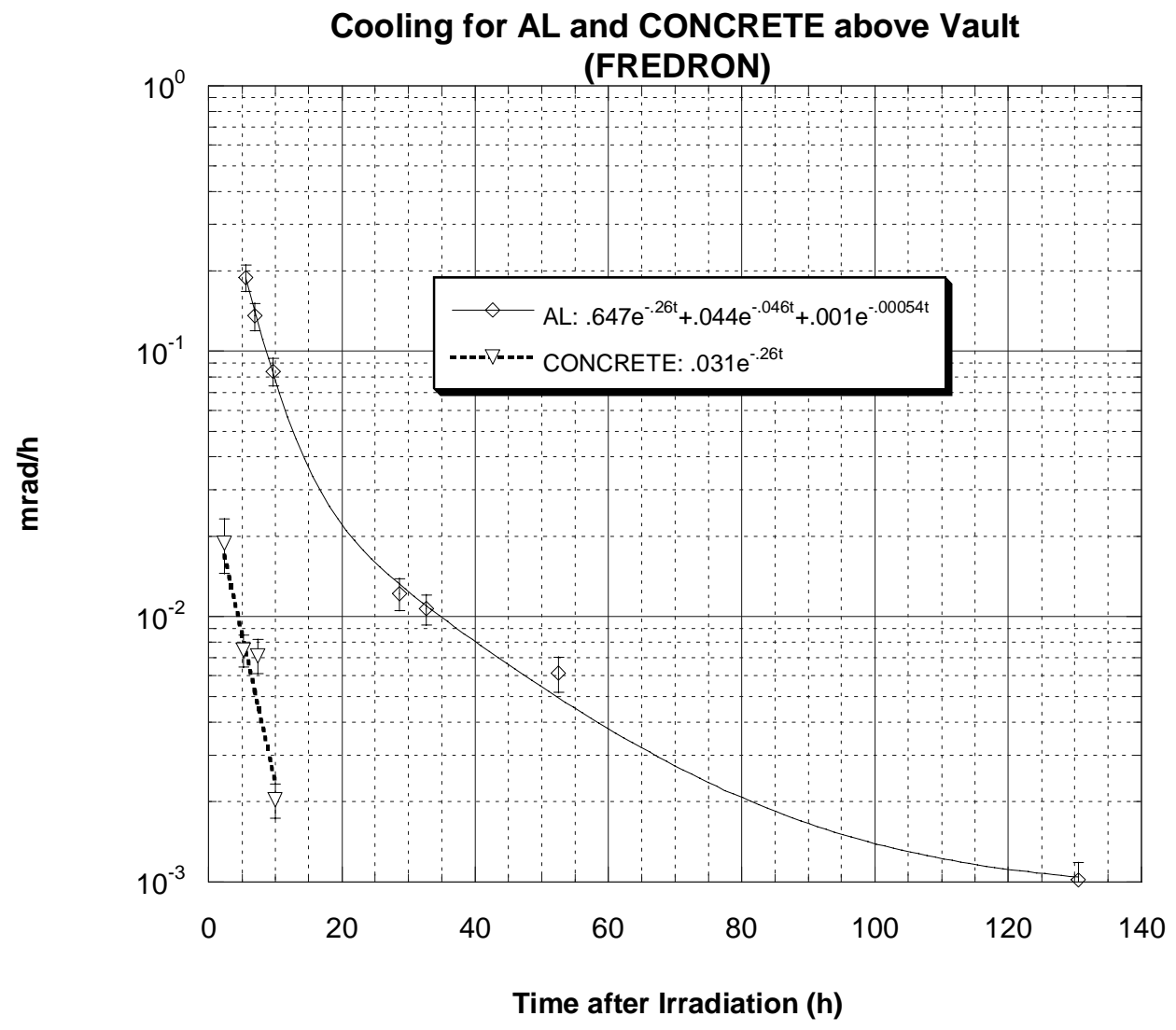

Fig. 10. Cooling of Al-like samples as a function of time after above vault-shielding irradiation. The data represent Fredron contact dose rate readings.

\section{(c). Comparison with MARS}

Rakhno, et al (RA01) report on a comparison of the time dependence (cooling) of the residual radiation discussed above with calculations based on the MARS and MCNP Monte Carlo codes. The AP0 target area including shielding was modeled, and calculations with the appropriate schedule of beam on and beam off times (see Section 2) performed for both in-vault and above-vault sample irradiations. The comparison with the in-vault results is excellent (see Figs. 4 and 6 of RA01). The above vault shielding measurements, on the other hand, are factors of 2 to 3 larger than the MARS calculation (see Figs. 5 and 6 of RA01); this sort of disagreement is, however, typical of comparisons between residual 
activation data and Monte Carlo codes for situations involving thick shielding. ${ }^{4}$ It is useful to point out that for the residual activation above the shielding, the contribution from neutrons streaming through the air gaps between modules and between the modules and the walls of the enclosure is important and must be accurately modeled, as they were in the reference (RA01).

\section{Foil Activation and Neutron Energy Spectra}

\section{(a). In-Vault Spectrum and Thermal Neutrons}

As mentioned, thin foils of $\mathrm{In}, \mathrm{Au}$, and $\mathrm{Au}$ covered with $\mathrm{Cd}$, were irradiated along with the samples discussed above and the radioactivity determined at the Radioisotope Analysis Facility. For the in-vault irradiation these activities were employed to unfold a neutron spectrum. The saturated activity for each isotope identified in the foil is related to the neutron spectrum $\Phi(\mathrm{E})$ (neutrons $\mathrm{cm}^{-2}-\mathrm{sec}^{-1}-\mathrm{MeV}^{-1}$ ) by the relation

$$
A_{s}=\int \Phi(E) R(E) d E
$$

Here, $R(E)=N \sigma(E)$ for each radionuclide averaged over each energy interval, with $\sigma(E)$ the reaction cross section for the production of the isotope, and $\mathrm{N}$ the number of atoms per gram. The nuclides identified in the irradiation were ${ }^{115} \mathrm{In},{ }^{198} \mathrm{Au},{ }^{196} \mathrm{Au},{ }^{195} \mathrm{Au}$, and ${ }^{194} \mathrm{Au}$. (The activities associated with ${ }^{193} \mathrm{Au}$ and ${ }^{192} \mathrm{Au}$, normally observed in neutron irradiation in similar configurations, were too small to be quantitatively obtained). Because the cross sections associated with the production of the isotopes effectively cover only the energy region up to about $60 \mathrm{MeV}$, the energy scale was broken up into 7 intervals that covered the range from $0.1 \mathrm{MeV}$ to $60 \mathrm{MeV}$ plus a bin from thermal energies to $0.1 \mathrm{MeV}$. The available data, therefore, yields only low-resolution spectra. Because of known uncertainties associated with unfolding spectra when the number of unknowns is larger than the data available, two unfolding codes (that apply somewhat different constraints in the unfolding process) BUNKI and LOUHI (LO84, RO80) were used in order to gain some confidence in the reasonableness of the results. The response functions $R(E)$ (see Eq. 1) were determined from known (see, e.g., GR78) neutron induced reaction cross sections by averaging over each energy bin. The unfolded spectrum is shown in Fig. 11. The results from BUNKI and LOUHI are nearly the same, suggesting that the unfolding process was reasonable. The unfolded results (per $10^{12}$ protons incident on the in-vault target) for energy intervals above $0.1 \mathrm{MeV}$, while similar in shape to the spectrum calculated from MARS, are however lower by factors of $2-5 .^{5}$

\footnotetext{
${ }^{4}$ Another source of discrepancy between measurements and calculations, particularly at locations outside of thick shielding, is inadequate data on the true composition of the shielding material. In the present case, the density of the iron shielding was taken as $7.87 \mathrm{~g} / \mathrm{cm}^{3}$ due to lack of other data, and the actual composition of the concrete sample was only known approximately.

${ }^{5}$ Note that the spectrum shown in Fig. 11 is somewhat different than that shown in Fig. 7 of the RA01. It represents a more recent calculation.
} 


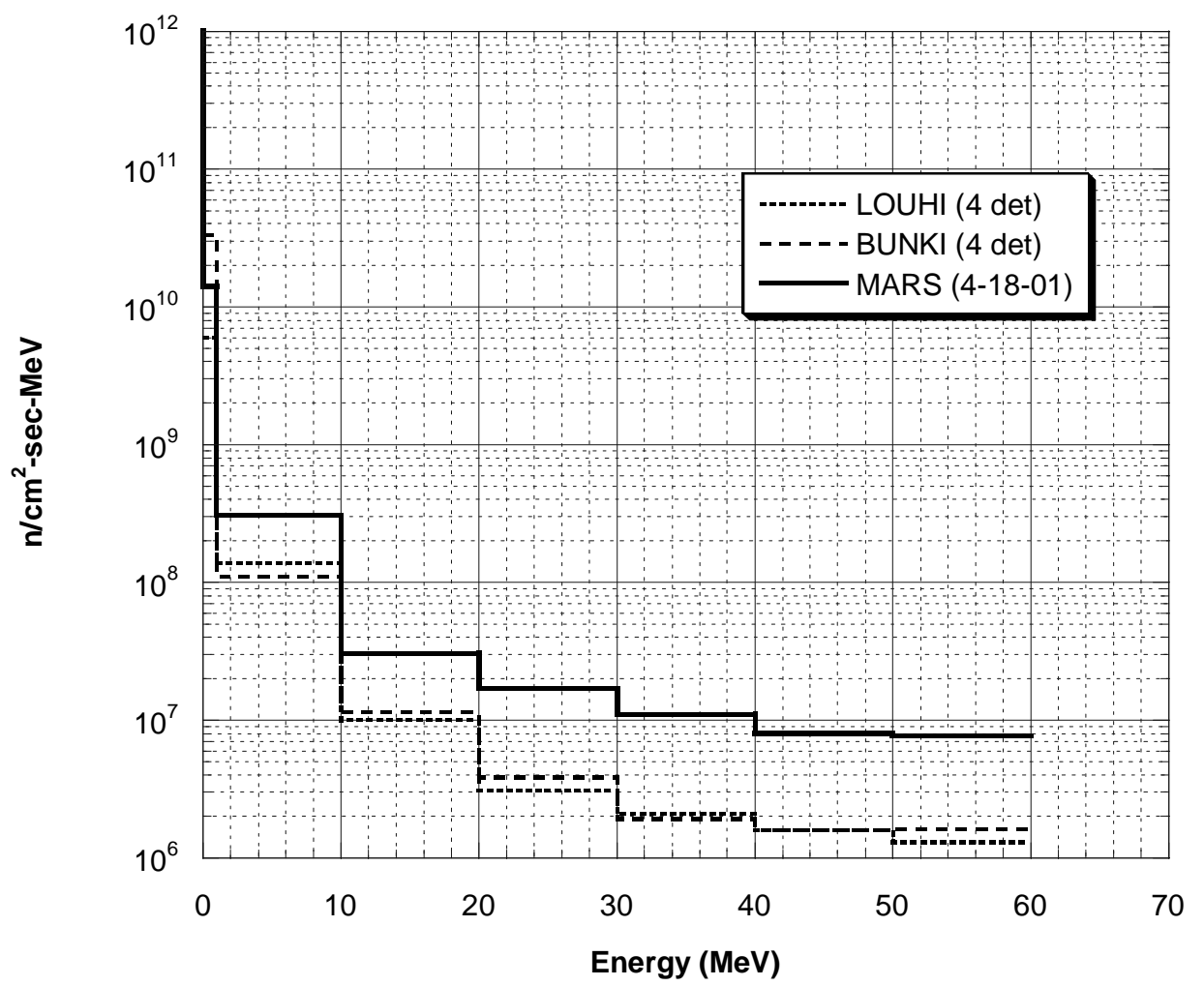

Fig. 11. Neutron spectrum (in units of $n-\mathrm{cm}^{-2}-\mathrm{sec}^{-1}-\mathrm{MeV}^{-1}$ ) within the vault, unfolded with the codes BUNKI and LOUHI compared with the MARS calculation.

It has been shown (see, e.g., AS86, BE64) that the activity due to thermal neutrons can be obtained from the measured foil activations by use of the $\mathrm{Cd}$ difference method. That is, the activity measured for the bare $\mathrm{Au}$ foil minus that measured for the $\mathrm{Cd}$ covered foil, with the $\mathrm{Cd}$ covered foil multiplied by a small correction called the $\mathrm{Cd}$ correction factor, equals the activity of thermal neutrons, $\mathrm{A}_{\mathrm{th}}$. For the approximate $\mathrm{Au}$ and $\mathrm{Cd}$ foil thicknesses used in the present measurements, the correction factor is estimated to be $\leq 1.08$ (AS86). The saturated activities for these foils from irradiation within the vault are shown in Table 2. Shown also in the Table is the thermal neutron flux, which is related to the thermal neutron activity by the expression shown in Eq. 2,

$$
\Phi_{\text {thermal }}=\frac{A_{\text {thermal }}}{N \sigma} \mathrm{n}-\mathrm{cm}^{-2}-\mathrm{sec}^{-1}
$$


Here $\mathrm{N}$ is the number of atoms/gram, and $\sigma$ is the production cross section of the given isotope (in this case, ${ }^{198} \mathrm{Au}$ ) for thermal neutrons, which is taken to be $99 \mathrm{~b}$. The neutron flux at thermal energies $(0.025 \mathrm{eV})$ has not been directly calculated with MARS. ${ }^{6}$

Table 2: Activity due to thermal neutrons, and thermal neutron flux.

\begin{tabular}{|c|c|c|c|}
\hline $\mathbf{A}_{\mathbf{A u}}$ & $\mathbf{A}_{\mathbf{A u}+\mathbf{C d}}$ & $\mathbf{A}_{\text {thermal }}$ & $\Phi_{\text {thermal }}$ \\
\hline$(\mathbf{B q} / \mathbf{g})$ & $\mathbf{( B q} / \mathbf{g})$ & $\mathbf{( B q} / \mathbf{g})$ & $\mathbf{( n / \mathbf { c m } ^ { 2 }}$-sec) \\
\hline $6.76 \times 10^{7}$ & $6.16 \times 10^{7}$ & $1.07 \times 10^{6}$ & $3.54 \times 10^{6}$ \\
\hline
\end{tabular}

\section{(b). Above-Vault Foil Activation and Thermal Neutrons}

The radioactivity of the $\mathrm{Au}$ and $\mathrm{Au}+\mathrm{Cd}$ foils was determined from the measurements above the steel shielding over the vault area. The foils had been placed in three locations close to each other but not at the same place. One set was placed on an Al tray; a second set in a $5.08 \mathrm{~cm}$ thick $\mathrm{CH}_{2}$ rectangular box (2" thick cave); the third in a $15.24 \mathrm{~cm}$ thick $\mathrm{CH}_{2}$ box (6" thick cave). Because the activation was not large, only the isotope ${ }^{198} \mathrm{Au}$ could be identified, so that a full neutron spectrum was not determined. However, the bare foil activation in the Al tray was measured, and the saturated activity (see Appendix 2 and Table 3 below) compared to a corresponding MARS calculation (RAK01).

Table 3. Measured activities of the $\mathrm{Au}$ and $\mathrm{Au}+\mathrm{Cd}$ foils at the three above-vault locations. The saturated activity was determined as indicated in Appendix 2.

\begin{tabular}{|c|c|c|c|c|}
\hline \multirow[t]{2}{*}{ LOCATION } & \multicolumn{2}{|c|}{ ACTIVITY (DATA) (Bq/g) } & \multicolumn{2}{|c|}{ SAT ACTIVITY $(\mathrm{Bq} / \mathrm{g})$} \\
\hline & $\mathrm{Au}$ & $\mathrm{Au}+\mathrm{Cd}$ & $\mathrm{Au}$ & $\mathrm{Au}+\mathrm{Cd}$ \\
\hline Al Tray & $8.40 \times 10^{5}$ & $5.77 \times 10^{5}$ & $1.93 \times 10^{6}$ & $1.33 \times 10^{6}$ \\
\hline 2" Thick Cave & $1.94 \times 10^{6}$ & $1.30 \times 10^{5}$ & $4.46 \times 10^{6}$ & $2.99 \times 10^{5}$ \\
\hline 6" Thick Cave & $1.33 \times 10^{5}$ & $1.06 \times 10^{4}$ & $3.06 \times 10^{5}$ & $2.44 \times 10^{4}$ \\
\hline
\end{tabular}

The saturated activity in the bare Au foil from the MARS calculation is $2.2 \times 10^{5} \mathrm{~Bq} / \mathrm{g}$. This value is about a factor of 9 lower than the saturated activity obtained from the measured activity for the foil in the Al tray as observed in Table 3.

With the neutron spectrum $\left(\mathrm{n} / \mathrm{cm}^{2}-\mathrm{sec}-\mathrm{MeV}\right)$ calculated above the vault shielding by MARS (see Fig. 8 in RA01), and response functions (essentially efficiencies for neutron detection) for $\mathrm{Au}$ foils in polyethylene $\left(\mathrm{CH}_{2}\right)$ boxes with different wall thicknesses (2" and 6 " thick in the current case), the saturated activities at the different locations could be calculated by use of Eq. (1) (with $\mathrm{R}(\mathrm{E})$, the response function, given in units of disintegration/g per $\mathrm{n} / \mathrm{cm}^{2}$ ) and compared with the measurements. Unfortunately, such data do not exist in the literature. However, response functions for $\mathrm{Au}$ foils within $\mathrm{CH}_{2}$ Bonner spheres are given in a compilation from the IAEA (GR90). We have, therefore, estimated the saturated activities on the perhaps dubious assumption that such response

\footnotetext{
${ }^{6}$ Even though thermal flux can be estimated from the calculated neutron spectrum (Fig. 7, RA01), the uncertainties associated with both the measurements and calculations are too large to make a useful comparison.
} 
functions for the 2.5" radius sphere and the 6" radius sphere can be used to represent those for 2" and 6" thick $\mathrm{CH}_{2}$ boxes respectively. Fig. 12 shows the product $\Phi(\mathrm{E}) \mathrm{R}(\mathrm{E})$ (from Eq. 1) plotted as a function of energy, and Table 4 shows the values of the integrals of these products for the bare foil, and for foils within the 5" and 12" diameter spheres.

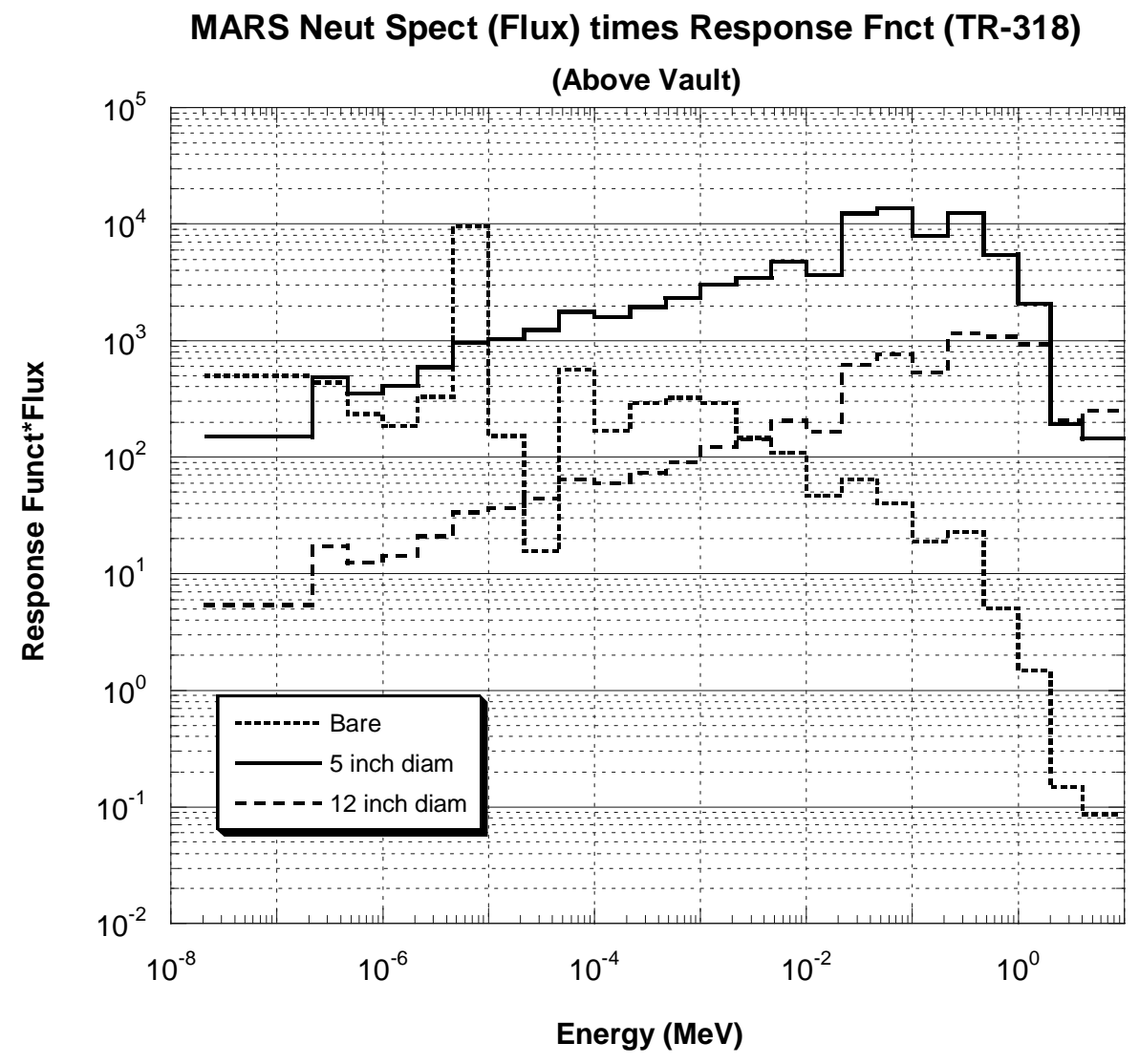

Figure 12: The product of the neutron spectrum (flux) above the vault from a MARS calculation of the spectrum and Bonner sphere response functions from IAEA TR \#318 (GR90).

Table 4: Comparison of the calculated integrals of the products shown in Fig. 12 with measured saturated activities.

\begin{tabular}{|c|c|c|c|c|}
\hline CAVE,SPHERE & INT(CALC) & MEASURED & RATIO(INT) & RATIO(MEAS) \\
\hline & $(\mathrm{Bq} / \mathrm{g})$ & $(\mathrm{Bq} / \mathrm{g})$ & & 1 \\
\hline Bare & $2.47\left(10^{4}\right)$ & $1.93\left(10^{6}\right)$ & 1 & 2.3 \\
\hline 2" th, 2.5" rad. & $1.31\left(10^{5}\right)$ & $4.46\left(10^{6}\right)$ & 5.3 & 0.16 \\
\hline 6" th., 6" rad. & $1.05\left(10^{4}\right)$ & $3.06\left(10^{5}\right)$ & 0.43 & \\
\hline
\end{tabular}

Also shown in Table 4 are the results from the activation measurements for the bare, 2 " thick cave, and the 6" thick cave foils. The ratios to the bare foil (that is, result normalized 
to that for the bare foil) are shown as well. Although the values for the calculated integral and the measured activities differ by more than an order of magnitude, the ratios to the bare foil agree in each case to within factors of 2-3. The use of response functions for Bonner Spheres to compare with measurements in rectangular boxes with the same $\mathrm{CH}_{2}$ thickness as the radius of the sphere, should not be taken too literally. The fact, however, that the agreement in the ratios is as good as is shown suggests that perhaps the mechanisms involved in the determination of the response functions are similar in both cases.

Finally, as mentioned, the activity due to thermal neutrons was obtained by use of the $\mathrm{Cd}$ difference method. From this the flux due to thermal neutrons was determined. The saturated activities for the various sets of foils and the thermal fluxes are shown in Table 5.

Table 5. Thermal neutrons at the above-vault locations.

\begin{tabular}{|c|c|c|}
\hline LOCATION & SAT. ACTIVITY (THERMAL) & FLUX (THERMAL) \\
\hline & $(\mathrm{Bq} / \mathrm{g})$ & $\left(\mathrm{n} / \mathrm{cm}^{2}-\mathrm{sec}\right)$ \\
\hline Al Tray & $4.94 \times 10^{5}$ & $1.63 \times 10^{6}$ \\
\hline 2" CH2 Cave & $4.14 \times 10^{6}$ & $1.365 \times 10^{7}$ \\
\hline 6" CH2 Cave & $2.8 \times 10^{5}$ & $9.23 \times 10^{5}$ \\
\hline
\end{tabular}

\section{Concluding Remarks}

Measurements of residual activity were performed for a number of different material samples at the AP0 vault area. The experiment and the results for the sample radioactivity as a function of time after irradiation (cooling) are shown in some detail for both in-vault and above-vault measurements, and are consistent for the most part with the decay of isotopes that are expected to be produced during the irradiation (see Appendix 1 and discussion in Section 3). Comparison of these results with calculations from the computer program MARS are excellent for in-vault measurements, and within factors of 2 or 3 for above-vault irradiations. They have been described in detail in RA01. Thin foils were used to unfold a neutron spectrum at the in-vault location, and comparison with MARS is shown in RA01. Because the irradiation time was not long enough to get definitive data, results above the vault shielding allowed only the activity of ${ }^{198} \mathrm{Au}$ to be measured. From this, the thermal neutron flux was obtained and such estimates may be useful for an understanding of the neutron fields at other locations with similar shielding configurations.

Finally, it may appear somewhat surprising that, as observed in Table 4, the activity of the foil in the 2"thick $\mathrm{CH}_{2}$ cave is higher than that for the bare foil. Such a result is however reproduced qualitatively by employing response functions for $\mathrm{Au}$ foils in $\mathrm{CH}_{2}$ Bonner Spheres (see Table 4). Since response functions essentially represent the efficiency of neutron detection for each detector-moderator combination (that is, Au foil surrounded by $\mathrm{CH}_{2}$ Bonner Sphere), it is perhaps not too unreasonable to expect the same qualitative results for foils inside of $\mathrm{CH}_{2}$ boxes although quantitatively the details are expected to be quite different. 


\section{Acknowledgment}

We thank I. Rakhno and N. Mokhov for performing the calculations discussed in this paper and for useful discussions. Thanks also to A. Wehmann and J. D. Cossairt for constructive comments.

\section{References}

AS86. ASTM Standard, "Standard Method for Determining Thermal Neutron Reaction and Fluence Rates by Radioactivation Techniques", Report E262-86 (1986).

BE64. K. H. Beckurts and K. Wirth, Neutron Physics, Sect. 12.2, p. 273-285, Springer Verlag, (1964).

CU97. V. Cupps and A. Elwyn, "Induced 11C Activity Buildup in Uniform Pulsed Beams", Fermilab-Rad Phys Note 130 (1997).

GR78. L. R. Greenwood, "Extrapolated Neutron Activation Cross Sections for Dosimetry to $44 \mathrm{MeV}$ ", Argonne National Lab ANL/FPP/TM-115 (1978).

GR90. R. V. Griffith, J. Palfalvi, and U. Madhvanath, "Compendium of Neutron Spectra and Detector Responses For Radiation Protection Purposes", Technical Report 318, International Atomic Energy Agency (1990).

LE00. A. Leveling, "Lithium Irradiation Experiment", Fermilab-PBAR Note 640 (2000).

LO84. K. Lowry and T. Johnson, "Modifications to Iterative Recursion Unfolding Algorithms and Computer Codes to Find More Appropriate Neutron Spectra", US Naval Research Laboratory NRL-5340 (1948).

MO95. N. V. Mokhov, “The MARS Code System User's Guide”, Fermilab-FN-628 (1995).

MO00. N. V. Mokhov and O. E. Krivosheev, "MARS Code Status", Fermilab-Conf00/181 (2000).

RA01. I. Rakhno, N. Mohkov, A. Elwyn, N. Grossman, M. Huhtinen, and L. Nicolas, "Benchmarking Residual Dose Rates in a NuMI-like Environment", FermilabConf-01-304-E (2001).

RAK01. I. Rakhno, Private Communication (2001).

RO80. J. T. Routti and J. V. Sandeberg, "General Purpose Unfolding LOUHI78 with Linear and Non-Linear Regularization”, Comp. Phys. Comm. 21, 119 (1980). 


\section{Appendix 1: Radionuclides in Samples}

The radioisotope analysis of the $2.54 \mathrm{~cm}$ diameter iron and steel samples from the invault irradiation is shown in this Table. The specific activity of each isotope is presented as a fraction of the total activity (Cols. 5, 9, 13), and also normalized to that of Mn-52 (Cols. 6, 10, and 14), which along with Cr-51 represents the principal isotopes observed.

\begin{tabular}{|c|c|c|c|c|c|c|c|c|c|c|c|c|c|}
\hline NUCLIDE & $\begin{array}{c}\mathrm{T} 1 / 2 \\
\text { (d) }\end{array}$ & $\begin{array}{c}\text { SPEC } \\
\text { ACT } \\
(\mathbf{p C i} / \mathbf{g}) \\
\end{array}$ & \begin{tabular}{|c|} 
ERR \\
$(\mathrm{pCi} / \mathrm{g})$
\end{tabular} & $\begin{array}{c}\text { FRACTION } \\
\text { of TOT } \\
\text { ACT } \\
\end{array}$ & $\begin{array}{c}\text { FRACTION } \\
\text { of } \mathrm{Mn}-52 \\
\mathrm{ACT} \\
\end{array}$ & $\begin{array}{c}\text { SPEC } \\
\mathbf{A C T} \\
(\mathbf{p C i} / \mathbf{g})\end{array}$ & $\begin{array}{c}\text { ERR } \\
(\mathbf{p C i} / \mathrm{g})\end{array}$ & $\begin{array}{c}\text { FRACTION } \\
\text { of TOT } \\
\text { ACT } \\
\end{array}$ & \begin{tabular}{|c|} 
FRACTION \\
of $\mathrm{Mn}-52$ \\
$\mathrm{ACT}$
\end{tabular} & \begin{tabular}{|c|} 
SPEC \\
ACT \\
$(\mathbf{p C i} / \mathrm{g})$ \\
\end{tabular} & $\mid \begin{array}{c}\text { ERR } \\
(\mathrm{pCi} / \mathrm{g})\end{array}$ & \begin{tabular}{|c|} 
FRACTION \\
of TOT \\
ACT \\
\end{tabular} & 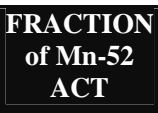 \\
\hline$\overline{F E}$ & & & & & & $\begin{array}{c}\text { A500 } \\
\text { STEEL }\end{array}$ & & & & \begin{tabular}{|c|}
1018 \\
STEEL
\end{tabular} & & & \\
\hline $\mathrm{Na}-24$ & $\overline{0.61}$ & 17569 & 1931 & 0.03 & 0.10 & 9964 & 1105 & 0.01 & 0.05 & 11749 & 1307 & 0.01 & 0.05 \\
\hline Al-28 & 0.87 & & & 0.00 & 0.00 & 1260 & 266 & 0.00 & 0.01 & 1688 & 311 & 0.00 & 0.01 \\
\hline $\mathrm{K}-42$ & 0.52 & 27226 & 4458 & 0.04 & 0.15 & & & 0.00 & 0.00 & 32532 & 5250 & 0.03 & 0.15 \\
\hline K-43 & 0.93 & 14685 & 1616 & 0.02 & 0.08 & 16488 & 1790 & 0.02 & 0.08 & 19822 & 2169 & 0.02 & 0.09 \\
\hline Sc-44 & 2.44 & 75744 & 11452 & 0.11 & 0.42 & 85803 & 12965 & 0.12 & 0.43 & 119218 & 18018 & 0.12 & 0.54 \\
\hline Sc-46 & 83.83 & 7745 & 915 & 0.01 & 0.04 & 9346 & 1035 & 0.01 & 0.05 & 9405 & 1083 & 0.01 & 0.04 \\
\hline Sc-47 & 3.341 & 43772 & 6624 & 0.06 & 0.25 & 47894 & 7241 & 0.06 & 0.24 & 83360 & 12608 & 0.09 & 0.38 \\
\hline Sc-48 & 1.82 & 11990 & 1113 & 0.02 & 0.07 & 13572 & 1128 & 0.02 & 0.07 & 14588 & 1278 & 0.02 & 0.07 \\
\hline V-48 & 15.98 & 87872 & 9411 & 0.13 & 0.49 & 99496 & 10641 & 0.13 & 0.49 & 103512 & 11086 & 0.11 & 0.47 \\
\hline $\mathrm{Cr}-48$ & 0.9 & 11023 & 1202 & 0.02 & 0.06 & 11973 & 1294 & 0.02 & 0.06 & 16064 & 2481 & 0.02 & 0.07 \\
\hline Cr-51 & 27.7 & 178445 & 27240 & 0.26 & 1.00 & 188884 & 28699 & 0.25 & 0.94 & 253546 & 38611 & 0.26 & 1.15 \\
\hline Mn-52 & 5.591 & 178554 & 15588 & 0.26 & 1.00 & 201104 & 17548 & 0.27 & 1.00 & 220483 & 19246 & 0.23 & 1.00 \\
\hline Mn-54 & 312.2 & 29820 & 4546 & 0.04 & 0.17 & 33440 & 5074 & 0.04 & 0.17 & 37186 & 5654 & 0.04 & 0.17 \\
\hline Co-55 & 0.73 & 8986 & 1013 & 0.01 & 0.05 & 15270 & 1526 & 0.02 & 0.08 & 19006 & 1899 & 0.02 & 0.09 \\
\hline Co-56 & 77.7 & & & & & 3544 & 422 & 0.00 & 0.02 & 3453 & 484 & 0.00 & 0.02 \\
\hline $\mathrm{Fe}-59$ & 44.5 & & & & & 2124 & 509 & 0.00 & 0.01 & 7336 & 1307 & 0.01 & 0.03 \\
\hline $\mathrm{Fe}-52$ & 0.34 & & & & & 4403 & 708 & 0.01 & 0.02 & & & & \\
\hline Br-76 & 0.675 & & & & & & & & & 9970 & 1514 & 0.01 & 0.05 \\
\hline Mo-99 & 2.75 & & & & & & & & & 2654 & 593 & 0.00 & 0.01 \\
\hline Sb-122 & 2.7 & & & & & & & & & 3913 & 734 & 0.00 & 0.02 \\
\hline
\end{tabular}

The results of radioisotope analysis for the $\mathrm{Al}$ and Concrete samples are shown in the Table below. The specific activity of each isotope is normalized to that of ${ }^{24} \mathrm{Na}$, which is by far the principal isotope.

\begin{tabular}{|c|c|c|c|c|c|c|c|c|c|c|c|}
\hline NUCLIDE & $\begin{array}{l}\mathrm{T} 1 / 2 \\
\text { (d) }\end{array}$ & $\begin{array}{c}\text { SPEC } \\
\text { ACT } \\
(\mathrm{pCi} / \mathrm{g})\end{array}$ & $\begin{array}{c}\text { ERR } \\
(\mathrm{pCi} / \mathrm{g})\end{array}$ & $\begin{array}{l}\text { FRACT } \\
\text { of TOT }\end{array}$ & $\begin{array}{l}\text { FRACT } \\
\text { of } \mathrm{Na}-24\end{array}$ & NUCLIDE & $\begin{array}{l}\text { T1/2 } \\
\text { (d) }\end{array}$ & $\begin{array}{c}\text { SPEC } \\
\text { ACT } \\
(\mathrm{pCi} / \mathrm{g})\end{array}$ & $\begin{array}{c}\text { ERR } \\
(\mathrm{pCi} / \mathrm{g})\end{array}$ & $\begin{array}{l}\text { FRACT } \\
\text { of TOT }\end{array}$ & $\begin{array}{l}\text { FRACT } \\
\text { of } \mathrm{Na}-24\end{array}$ \\
\hline AL & & & & & & CONCRETE & & & & & \\
\hline $\mathrm{Be}-7$ & 53.29 & 83268 & 16509 & 0.011 & 0.01 & Be-7 & 53.29 & 279062 & 42580 & 0.154 & 0.21 \\
\hline $\mathrm{Na}-24$ & 0.61 & 7747526 & 827674 & 0.983 & 1.00 & $\mathrm{Na}-24$ & 0.61 & 1346422 & 144025 & 0.744 & 1.00 \\
\hline $\mathrm{Na}-22$ & 950.35 & 23742 & 4618 & 0.003 & 0.00 & $\mathrm{Na}-22$ & 950.35 & 10536 & 1921 & 0.006 & 0.01 \\
\hline \multirow[t]{8}{*}{ Mn-54 } & 312.2 & 26916 & 4695 & 0.003 & 0.00 & Mn-54 & 312.2 & 2302 & 863 & 0.001 & 0.00 \\
\hline & & & & & & Mn-52 & 5.591 & 7179 & 807 & 0.004 & 0.01 \\
\hline & & & & & & $\mathrm{Mg}-28$ & 0.87 & 7257 & 1152 & 0.004 & 0.01 \\
\hline & & & & & & $\mathrm{K}-42$ & 0.52 & 59340 & 11846 & 0.033 & 0.04 \\
\hline & & & & & & K-43 & 0.93 & 69727 & 5621 & 0.039 & 0.05 \\
\hline & & & & & & $\mathrm{Ca}-47$ & 4.536 & 16939 & 2937 & 0.009 & 0.01 \\
\hline & & & & & & V-48 & 15.98 & 6568 & 1017 & 0.004 & 0.00 \\
\hline & & & & & & Br- -82 & 1.47 & 4234 & 809 & 0.002 & 0.00 \\
\hline
\end{tabular}


Along with the sample disks, the so-called "shavings from the green block", which are essentially steel, was irradiated in-vault. For completeness the results of the radioisotope analysis is shown in the Table below, but not discussed further.

\begin{tabular}{|c|c|c|c|l|l|}
\hline NUCLIDE & T1/2 $\mathbf{2}(\mathbf{d})$ & \multicolumn{1}{|l|}{ SPEC ACT (pCi/g) } & ERR (pCi/g) & FRACT of TOT & FRACT of Mn-52 \\
\hline SHAVINGS & & & & & \\
& & & & & \\
\hline Be-7 & 53.29 & & & & \\
\hline Na-24 & 0.61 & 111554 & 27561 & $\mathbf{0 . 0 2}$ & $\mathbf{0 . 0 8}$ \\
\hline Al-28 & 0.87 & 23995 & 20451 & $\mathbf{0 . 0 3}$ & $\mathbf{0 . 1 3}$ \\
\hline K-43 & 0.93 & 179730 & 19484 & $\mathbf{0 . 0 3}$ & $\mathbf{0 . 1 2}$ \\
\hline Sc-44 & 2.44 & 844155 & 132905 & $\mathbf{0 . 1 3}$ & $\mathbf{0 . 5 8}$ \\
\hline Sc-46 & 83.8 & 82737 & 9259 & $\mathbf{0 . 0 1}$ & $\mathbf{0 . 0 6}$ \\
\hline Sc-47 & 3.34 & 456902 & 69075 & $\mathbf{0 . 0 7}$ & $\mathbf{0 . 3 1}$ \\
\hline Sc-48 & 1.82 & 108843 & 9862 & $\mathbf{0 . 0 2}$ & $\mathbf{0 . 0 7}$ \\
\hline V-48 & 15.98 & 821046 & 87874 & $\mathbf{0 . 1 3}$ & $\mathbf{0 . 5 7}$ \\
\hline Cr-48 & 0.9 & 116280 & 12597 & $\mathbf{0 . 0 2}$ & $\mathbf{0 . 0 8}$ \\
\hline Cr-51 & 27.7 & 1558575 & 237307 & $\mathbf{0 . 2 4}$ & $\mathbf{1 . 0 7}$ \\
\hline Mn-52 & 5.59 & 1451757 & 126713 & $\mathbf{0 . 2 2}$ & $\mathbf{1 . 0 0}$ \\
\hline Fe-52 & 0.34 & 36712 & 6094 & $\mathbf{0 . 0 1}$ & $\mathbf{0 . 0 3}$ \\
\hline Mn-54 & 312.2 & 220206 & 33559 & $\mathbf{0 . 0 3}$ & $\mathbf{0 . 1 5}$ \\
\hline Co-55 & 0.73 & 132729 & 13425 & $\mathbf{0 . 0 2}$ & $\mathbf{0 . 0 9}$ \\
\hline Co-56 & 77.7 & 43704 & 5037 & $\mathbf{0 . 0 1}$ & $\mathbf{0 . 0 3}$ \\
\hline Co-57 & 271.8 & 10830 & 2247 & $\mathbf{0 . 0 0}$ & $\mathbf{0 . 0 1}$ \\
\hline Ni-57 & 1.5 & 77900 & 8731 & $\mathbf{0 . 0 1}$ & $\mathbf{0 . 0 5}$ \\
\hline Co-58 & 70.9 & 37879 & 6743 & $\mathbf{0 . 0 1}$ & $\mathbf{0 . 0 3}$ \\
\hline Fe-59 & 44.5 & 10372 & 3579 & $\mathbf{0 . 0 0}$ & $\mathbf{0 . 0 1}$ \\
\hline Co-60 & 1925 & 17249 & 2911 & $\mathbf{0 . 0 0}$ & $\mathbf{0 . 0 1}$ \\
\hline
\end{tabular}

For the above-vault irradiation, there are considerably fewer radioisotopes produced since the activation is (mainly) due only to neutrons. For the $\mathrm{Al}$ sample, ${ }^{24} \mathrm{Na}$ is the only isotope identified. For concrete, $42 \%$ of the total activity is due to ${ }^{42} \mathrm{~K}, 56 \%$ is ${ }^{24} \mathrm{Na}$, and $2 \%$ is ${ }^{46} \mathrm{Sc}$. The results for the iron and steel samples are shown in the Table below.

\begin{tabular}{|c|c|c|c|c|c|c|c|c|c|c|}
\hline NUCLIDE & $\begin{array}{c}\text { T1/2 } \\
\text { (d) }\end{array}$ & $\begin{array}{c}\text { SPEC ACT } \\
(\mathrm{pCi} / \mathrm{g})\end{array}$ & $\begin{array}{c}\text { ERR } \\
(\mathbf{p C i} / \mathrm{g})\end{array}$ & $\begin{array}{c}\text { FRACTION } \\
\text { of TOT } \\
\text { ACT }\end{array}$ & $\begin{array}{c}\text { SPEC ACT } \\
(\mathbf{p C i} / \mathrm{g})\end{array}$ & $\begin{array}{c}\text { ERR } \\
(\mathrm{pCi} / \mathrm{g})\end{array}$ & \begin{tabular}{|c|} 
FRACTION \\
of TOT \\
ACT \\
\end{tabular} & $\begin{array}{c}\text { SPEC ACT } \\
(\mathrm{pCi} / \mathrm{g})\end{array}$ & $\begin{array}{c}\text { ERR } \\
(\mathbf{p C i} / \mathrm{g})\end{array}$ & $\begin{array}{c}\text { FRACTION } \\
\text { of TOT } \\
\text { ACT }\end{array}$ \\
\hline FE & & & & & A500 STEEL & & & 1018STEEL & & \\
\hline Cr-51 & & & & & & & & 118 & 54 & 0.01 \\
\hline Mn-52 & 5.59 & 4 & 1.5 & 0.01 & & & & & & \\
\hline Mn-56 & 0.107 & & & & 19222 & 1685 & 0.92 & 7761 & 686 & 0.92 \\
\hline $\mathrm{Fe}-59$ & 44.5 & 480 & 52 & 0.99 & 1268 & 139 & 0.08 & 566 & 63 & 0.07 \\
\hline Co-60 & 1925 & & & & & & & 30 & 5 & 0.00 \\
\hline
\end{tabular}




\section{Appendix 2. The Saturation Correction for the Above Vault Foil Irradiation}

As mentioned, the foils above the vault were irradiated on and off from the end of June, 2000 to the end of October, 2000. During this period it is estimated that on the average the proton beam was on the target in the vault for 16 hours and then was off for 26 hours during the four-month irradiation time. In other words, the irradiation had a period of 42 hours between "pulses." Based on this assumption the measured foil activities were corrected to saturation as follows.

For a pulsed beam the measured activity (per gram) A, corrected for decay from the end of irradiation (including during the time of foil counting), can be written (CU97) as

$$
A=A_{s}\left[\frac{1-\exp (-\lambda t)}{1-\exp \left(-\lambda t_{b}\right)}\left(1-\exp \left(-n \lambda t_{b}\right)\right],\right.
$$

where $t=$ beam-on time, $t_{c}=$ cooling time following beam-on, $t_{b}=t+t_{c}$ is the period between beam-on irradiations, $\mathrm{n}=$ total number of beam-on periods, and $\lambda$ is the decay constant for

${ }^{198} \mathrm{Au}$. ( $\mathrm{T}_{1 / 2}=2.69$ days, $\left.\lambda=0.107 \mathrm{hr}^{-1}\right)$. The saturated activity $\mathrm{A}_{\mathrm{s}}$ can easily be determined from this expression. The results for all foil locations are shown in Table 3 in the text. 